\title{
Micro-optodes in sea ice: a new approach to investigate oxygen dynamics during sea ice formation
}

\author{
Thomas Mock ${ }^{1, *}$, Gerhard S. Dieckmann ${ }^{1}$, Christian Haas ${ }^{1}$, Andreas Krell ${ }^{1}$, \\ Jean-Louis Tison ${ }^{2}$, Andre L. Belem ${ }^{1}$, Stathis Papadimitriou ${ }^{3}$, David N. Thomas ${ }^{3}$
}

${ }^{1}$ Alfred-Wegener-Institute for Polar and Marine Research, Am Handelshafen 12, 27570 Bremerhaven, Germany

${ }^{2}$ Département des Sciences de la Terre et de l'Environnement, Université Libre de Bruxelles, 50 Avenue Franklin D. Roosevelt, 1050 Bruxelles, Belgium

${ }^{3}$ School of Ocean Sciences, University of Wales-Bangor, Menai Bridge, Anglesey LL59 5AB, Wales, UK

\begin{abstract}
Oxygen micro-optodes were used to measure oxygen dynamics directly within the microstructure of sea ice by freezing the sensors into the ice during its formation. The experiment was conducted in a $4 \mathrm{~m}^{3}$ mesocosm filled with artificial seawater and inoculated with a unialgal culture of the common Antarctic ice diatom Fragilariopsis cylindrus (Bacillariophyceae) to a final chlorophyll a (chl a) concentration of $11 \mathrm{\mu g} \mathrm{l}^{-1}$. Ice growth was initiated $7 \mathrm{~d}$ after inoculation by reducing the air temperature to $-10 \pm 2{ }^{\circ} \mathrm{C}$ and terminated $17 \mathrm{~d}$ later. The final ice thickness was $27 \mathrm{~cm}$. One optode was frozen into grease ice and 2 others into the skeletal layer of the growing ice sheet. Increasing oxygen concentrations during ice crystal formation at the water surface and the ice-water interface revealed a strong inclusion of oxygen, which was either physically trapped and/or the result of photosynthesising diatoms. The major portion of oxygen was present as gas bubbles due to supersaturation as a result of increasing salinity and oxygen production by diatoms. An increase in salinity due to a concurrent decrease in ice temperatures during subsequent sea ice development reduced the maximum concentration of dissolved oxygen within brine. Thus, dissolved oxygen concentrations decreased over time, whereas gaseous oxygen was released to the atmosphere and seawater. The sensors are a significant advance on more conventional microelectrodes, because the recordings can be temperature and salinity compensated in order to obtain precise measurements of oxygen dynamics with regard to total (dissolved and gaseous) and dissolved oxygen in sea ice. Optodes do not consume oxygen during measurement over a long period under extreme conditions, which is another advantage for long-term deployment in the field.
\end{abstract}

KEY WORDS: Fragilariopsis cylindrus · Oxygen · Methods · Micro-optodes · Sea ice $\cdot$ Biogeochemistry

Resale or republication not permitted without written consent of the publisher

\section{INTRODUCTION}

Ecology of sea ice has been studied intensively for several decades (e.g. Meguro 1962, Bunt \& Lee 1970, Alexander et al. 1974, Horner 1985, Dieckmann et al. 1991, Legendre et al. 1992, Gleitz et al. 1995, Arrigo et al. 1997, Melnikov 1997, Mock \& Gradinger 1999,

*E-mail: tmock@awi-bremerhaven.de
Lizotte 2001, Brierley \& Thomas 2002, Trenerry et al. 2002), but it is only in recent years that sea ice biogeochemistry has received attention (Günther \& Dieckmann 1999, Günther et al. 1999, Thomas et al. 2001, Thomas \& Dieckmann 2002). Due to the lack of comprehensive temporal studies, the relationships between abiotic factors (e.g. irradiance, temperature, nutrients, ice texture, ice thickness) and biological processes (e.g. carbon uptake by algae, remineralisation), are still unclear. For instance, several workers (Gleitz 
et al. 1995, Günther et al. 1999) measured phosphate accumulation as a consequence of heterotrophic production in combination with substantial dissolved inorganic carbon (DIC) depletion and strong oxygen oversaturation. This is contradictory to the expected oxygen consumption by microzooplankton and bacteria, of which the latter frequently exceeds primary production of microalgae (Grossmann \& Dieckmann 1994). Such discrepancies can be best addressed by defined laboratory ice experiments where the concepts of brine channel architecture and internal surface area as the basis for interactions of organisms, colonisation and biogeochemical processes can be studied in detail (Krembs et al. 2000, 2001). Cryo-microscopical methods are now available which enable the visualisation of microorganisms in their brine channel habitat (Junge et al. 2001). Such developments are superb aids to define complex physicochemical and biogeochemical interactions within the intricate sea ice microbial networks. However, despite these developments, we are still unable to determine chemical or physical conditions in undisturbed brine channels. Consequently, our knowledge is mainly restricted to bulk parameters resulting in the development of concepts with unclear details about prevailing environmental conditions in the network of brine channels, pockets or bubbles. The main reason for this serious shortcoming is the inaccessibility of the ice interior due to texture and rigid nature of the ice.

Many of the problems facing the sea ice researcher are similar to those encountered when measuring production processes and fluxes across biological films and surface sediments (Krembs et al. 2000, 2001). The technological progress that has been revolutionary in the study of biofilms and sediments is the most appropriate source of tools for a new era in sea ice research. One of the most striking advances in the past $15 \mathrm{yr}$ has been the development of microelectrodes for the study of diffusive boundary layers and profiles of dissolved gases with remarkably fine scale resolution (Herman \& Rechnitz 1974, Revsbech et al. 1980, Jörgensen \& Revsbech 1985, Revsbech \& Jörgensen 1986, Klimant et al. 1995, De Beer et al. 1997).

Several studies have used microelectodes in sea ice investigations (McMinn \& Ashworth 1998, McMinn et al. 2000, Kühl et al. 2001, Rysgaard et al. 2001, Glud et al. 2002, Trenerry et al. 2002). These microelectrodes were constructed exclusively to measure dissolved oxygen, however, they were not deployed directly in brine channels (McMinn et al. 2000). They are able to penetrate loose layers of ice crystals at the ice-water interface and the bottom few millimetres of sea ice which encompasses the bottom sea ice assemblages that are common in land fast ice (Rysgaard et al. 2001). In situ determination of dissolved oxygen, and there- fore photosynthesis and respiration, is of fundamental importance in understanding the driving forces behind biogeochemical cycling within ice assemblages (Gleitz et al. 1995, Günther et al. 1999, Glud et al. 2002). Chemical processes such as redox-reactions are strongly influenced by the presence or absence of oxygen. The oxygen concentration is also influenced by physical processes within brine channels (Tsurikov 1979). Thus, oxygen is central in the interaction between physicochemical and biological processes (Jörgensen \& Revsbech 1985).

Unfortunately, there are major limitations to the use of microelectrodes within brine channels of sea ice. They are not flexible and consume oxygen, which results in a strong influence on oxygen concentrations within small pore spaces (Klimant et al. 1995, 1997, Gouin et al. 1997). To overcome these constraints and to further develop our understanding of oxygen dynamics, we have investigated the use of oxygen micro-optodes in artificially produced sea ice. An array of micro-optodes was frozen into the ice as it was growing. Temperature and salinity compensation of the signals was possible by simultaneous freezing of a chain of thermistors in the same sea ice depth. Salinity was calculated based on temperature (Assur 1960). The deployment of the sensors within the brine channels for ca. $17 \mathrm{~d}$ indicated that oxygen concentrations were influenced by freezing of sea water, brine salinity, diffusive gas exchange and biological activity.

\section{MATERIALS AND METHODS}

Set-up of mesocosm experiment. The optodes were tested in a $4 \mathrm{~m}^{3}$ polyethylene tank (mesocosm without exchange of water) placed in a large environmental basin at HSVA (Hamburgische Schiffbau- und Versuchsanstalt) in Hamburg, Germany. The mesocosm was filled with artificial seawater (Instant Ocean Salt) to a final salinity of 34 and f/2 nutrients (Guillard \& Ryther 1962). At all times, the water was well mixed using a filterless water pump. Light was provided from above by fluorescence tubes (Osram, ultra-white). Surface irradiance at the ice surface was adjusted to $34 \mu \mathrm{mol}$ photons $\mathrm{m}^{-2} \mathrm{~s}^{-1}$ for the entire period of the experiment. The mesocosm (water temperature $0^{\circ} \mathrm{C}$ ) was inoculated with batch cultures of non-axenic Fragilariopsis cylindrus (Bacillariophyceae), originally isolated from the Antarctic, to a final chlorophyll a ( $\mathrm{chl} \mathrm{a}$ ) concentration of $11 \mu \mathrm{g} \mathrm{l}^{-1}$. This relatively high initial algal concentration was chosen to initiate a dense algal bloom in the ice. Ice growth was initiated $7 \mathrm{~d}$ after inoculation by reducing the room temperature to $-10 \pm 2{ }^{\circ} \mathrm{C}$ and initiating ice crystal formation by fine water spray over the water surface (Haas et al. 1999, Krembs et al. 2001). 
Physical, chemical and biological measurements. Air temperatures were logged every 10 min using a TinyTalk thermometer located $20 \mathrm{~cm}$ above the ice surface in a parallel tank. Ice and water temperatures were measured at intervals of $6 \mathrm{~s}$ using 2 thermistor sticks deployed near the optode array. They were composed of 10 Siemens K17 thermistors with a vertical spacing of $2 \mathrm{~cm}$ beginning $2 \mathrm{~cm}$ above the air-water interface. The thermistor tips extended horizontally by about $1.5 \mathrm{~cm}$ away from the vertical stick to avoid ice growth artefacts. Ice thickness measurements were performed at irregular time intervals by inserting a dipstick inside small drill holes.

Surface irradiance (photosynthetically active radiation [PAR]) was measured with a Li-Cor 1000 radiometer and a $4 \pi$ sensor, whereas the underwater light field was recorded with a miniature Fiber Optic Spectrometer (Ocean Optics) fitted with a CC-3 cosine-corrected irradiance probe. This probe was placed $30 \mathrm{~cm}$ below the water surface. Readings were taken at irregular time intervals but parallel to the oxygen measurements.

Ice cores for the determination of chl $a_{\text {, phaeopig- }}$ ments, and bulk ice and brine salinities were drilled manually with a $12 \mathrm{~cm}$ ice auger at irregular time intervals throughout the ice phase of the experiment. The cores were sectioned into 5 to $7 \mathrm{~cm}$ sections and centrifuged for $15 \mathrm{~min}$ at $-5^{\circ} \mathrm{C}$ to extract the brine (Krembs et al. 2001). The salinities of the brine and remaining melted ice were measured using a WTW LF 191 conductivity meter. For the determination of chl $a$ and phaeopigments, brine and the remaining melted ice were filtered onto Whatman GF/F filters and analysed fluorometrically with a Turner Designs Model 10-AU digital fluorometer after Arar \& Collins (1992).

The Type A micro-optodes (PreSense, Precision Sensing $\mathrm{GmbH}$ ) have a measuring range from 0 to $500 \%$ air saturation. They possess fibre tips of ca. $40 \mu \mathrm{m}$ which were coated with black silicon to ensure stability and to suppress any optical effects from the surrounding sea ice. The optical fibre was fixed in a syringe and guided through the needle $(10 \mathrm{~cm}$ length). The micro-optodes were 2 point calibrated at $-1^{\circ} \mathrm{C}$ in aerated artificial sea water with a salinity of $34(100 \%$ air saturation) and a solution of $0.5 \% \mathrm{NaSO}_{3}(0 \%$ oxygen) before starting the experiment. A re-calibration of the optodes was not possible because the cables had to be severed for the thin section analysis needed to determine the position of the optodes in the ice. Four sensors were deployed at discreet intervals attached to a wooden support placed in a corner of the mesocosm (Fig. 1). The first sensor was placed $4 \mathrm{~cm}$ below the surface of the water (Optode 4), the second $15 \mathrm{~cm}$ below (Optode 15), the third $25 \mathrm{~cm}$ (Optode 25) and one in $60 \mathrm{~cm}$ depth (Optode 60) (Fig. 1). The sensor tips extended horizontally by about $12 \mathrm{~cm}$ from the vertical stick. Readings were taken with a Microx I (PreSens) at irregular time intervals with a maximum frequency of 3 times a day. Microx I measures the luminescence lifetime of the immobilised luminophore as the oxygen dependent parameter. Measurements are not affected by bending the fibre or the optical properties of the sample. Furthermore, intensity fluctuations of the light sources or bleaching effects of the indicators have no impact on the lifetime measurements. The Microx I uses a phase-modulation technique to evaluate the lifetime of the indicators. The oxygen content as \% airsaturation can be calculated using Eq. (1):

$$
\left[\mathrm{O}_{2}\right]=\frac{1-\frac{\tan \Phi}{\tan \Phi_{0}}}{K_{\mathrm{SV}}\left\{\frac{\tan \Phi}{\tan \Phi_{0}}-0.11\right\}}
$$

where $\Phi_{0}$ is the phase angle of oxygen free water, $\Phi$ is the measured phase angle, $K_{\mathrm{SV}}$ is the Stern-Volmer constant and $\left[\mathrm{O}_{2}\right]$ is the oxygen content in \% air saturation.

The conversion of $\%$ air saturation into $\mu \mathrm{mol} \mathrm{O}_{2} \mathrm{l}^{-1}$ can be calculated as in Eq. (2):

$$
\begin{aligned}
\mathrm{O}_{2}\left(\mu \mathrm{mol} \mathrm{l}^{-1}\right) & =\left[\frac{p_{\mathrm{atm}}-p_{\mathrm{w}}(T)}{p_{\mathrm{N}}} \times \frac{\% \text { air saturation }}{100}\right. \\
& \left.\times 0.2095 \times \alpha\left(T_{i} S\right) \times 1000 \times \frac{M\left(\mathrm{O}_{2}\right)}{V_{\mathrm{M}}}\right] \times 31.25
\end{aligned}
$$

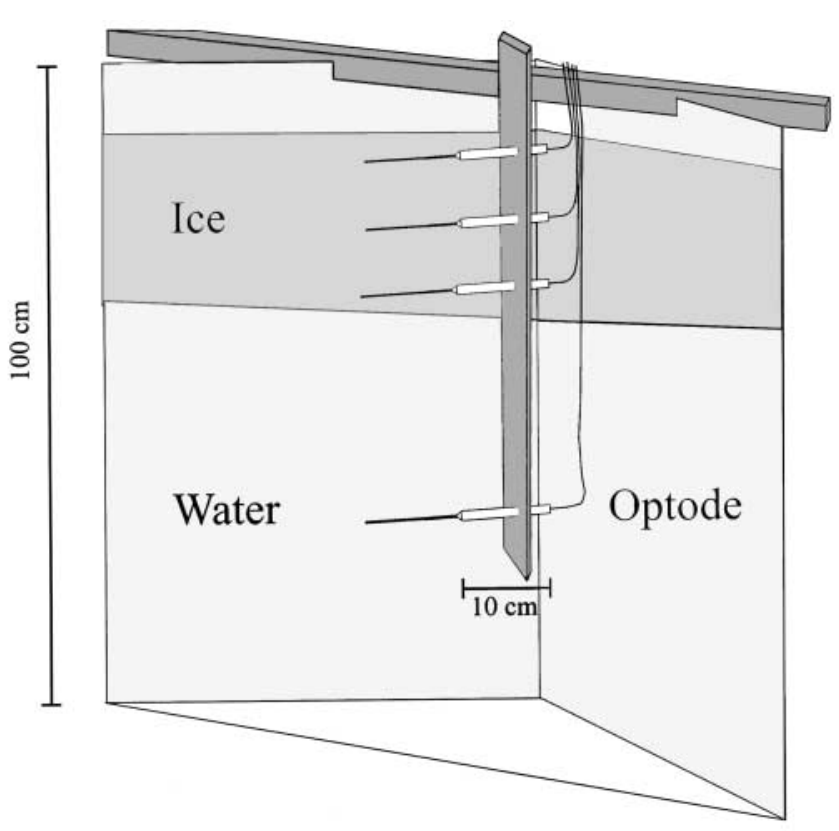

Fig. 1. Set-up of the oxygen micro-optode array in 1 corner of the mesocosm. The first sensor was placed $4 \mathrm{~cm}$ below the surface (Optode 4), the second $15 \mathrm{~cm}$ below (Optode 15), the third $25 \mathrm{~cm}$ (Optode 25) and one was placed at $60 \mathrm{~cm}$ depth (Optode 60). Ice thickness reached $27 \mathrm{~cm}$ at the end of the experiment 


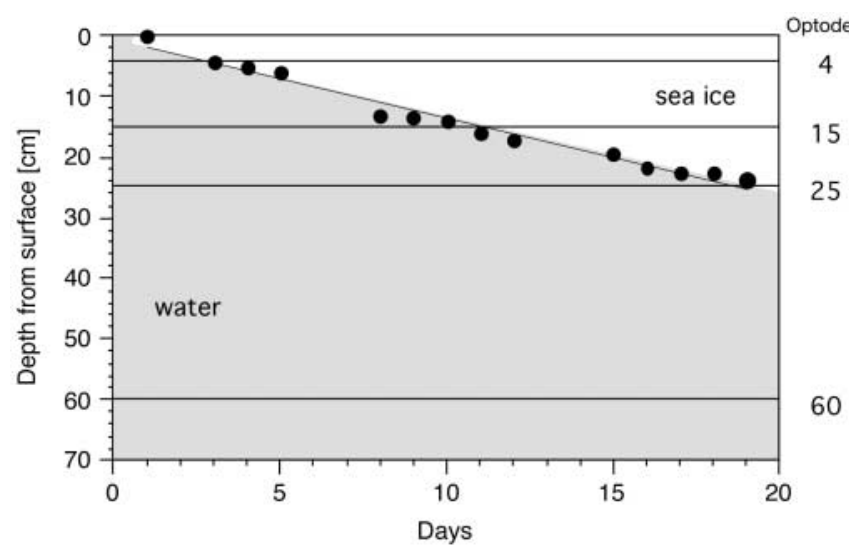

Fig. 2. Ice thickness during the experiment. Optode 4 was frozen on Day 3 in a grease ice layer, whereas Optode 15 was frozen on Day 10 and Optode 25 on Day 17 in the skeletal layer of sea ice. Optode 60 was the reference for seawater

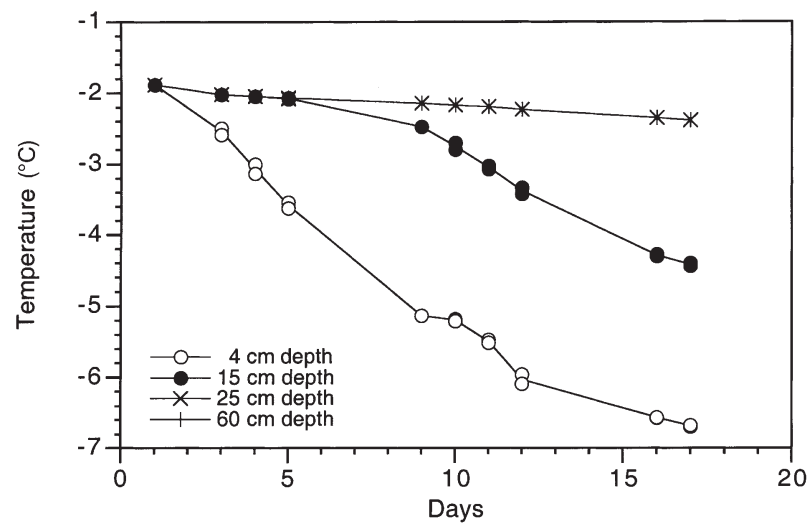

Fig. 3. Temperature shift during oxygen measurement in those depths where the optodes were placed. Optodes 4, 15,

25 and 60 are at 4,15, 25 and $60 \mathrm{~cm}$ depth, respectively

where $p_{\text {atm }}$ is the actual atmospheric pressure, $p_{\mathrm{N}}$ is the standard pressure (1013 mbar), 0.2095 is the volume content of oxygen in air, $p_{\mathrm{w}}(T)$ is the vapour pressure of water at temperature $T$ given in Kelvin, $M\left(\mathrm{O}_{2}\right)$ is the molecular mass of oxygen $\left(32 \mathrm{~g} \mathrm{~mol}^{-1}\right), V_{\mathrm{M}}$ is the molar volume $\left(22.414 \mathrm{l} \mathrm{mol}^{-1}\right)$, and $\alpha(T ; S)$ is the Bunsen absorption coefficient at temperature $T$ (Kelvin) and salinity $S$.

The conversion of $\%$ air saturation into $\mu \mathrm{mol} \mathrm{O}_{2} \mathrm{l}^{-1}$ can only be calculated by considering the influence of temperature and salinity changes during sea ice formation and subsequent growth. Both parameters $(T ; S)$ have a strong influence on the concentration of dissolved oxygen in brine (Sherwood et al. 1991). The solubility of oxygen decreases with increasing salt concentrations and increases with decreasing temperatures. Consequently, a temperature compensation had to be conducted by using thermistors. The temperature data were also used to calculate brine salinity (Assur 1960) and chlorinity using Eq. (3):

$$
\left[\mathrm{Cl}^{-}\right]=\frac{S_{\mathrm{b}}}{1.805}-0.03
$$

where $S_{\mathrm{b}}$ is the brine salinity.

This is necessary to compensate for the salting-out effect with the Bunsen absorption coefficient $\alpha\left(T_{;} S_{\mathrm{b}}\right)$ using Eq. (4):

$$
\begin{aligned}
{\left[\alpha\left(T_{;} S_{\mathrm{b}}\right)\right]=} & \exp \left[\left(A+\frac{B}{T}+C \times \ln T+D \times T\right)-\left[\mathrm{Cl}^{-}\right]\right. \\
& \left.\times\left(P+\frac{Q}{T}+R \times \ln T+S \times T\right)\right]
\end{aligned}
$$

where $A$ is $-7.424, B$ is $4.417 \times 10^{3}, C$ is $-2.927, D$ is $4.238 \times 10^{-2}, P$ is $-1.288 \times 10^{-1}, Q$ is $53.44, R$ is $-4.442 \times$ $10^{-2}$ and $S$ is $7.145 \times 10^{-4}$. A-D and $P-S$ are coefficients based on measurements and polynomial fits (Instruction Manual for Microx TX, PreSence Precision Sensing).

Ten temperature measurements (60 s) were used for each reading point of oxygen. The average of the temperature/chlorinity data was used to compensate the oxygen measurements. More details on the measuring principle, calculation as well as the optodes themselves are available at www.PreSens.de. Oxygen titration according to the Winkler method (Strickland \& Parsons 1972) was conducted on water samples from below sea ice at irregular time intervals in order to compare the water measurements taken with Optode 60. This comparison was not possible for the ice samples.

At the end of the experiment, an ice block in which the optodes were frozen was cut out from the ice sheet in order to determine the microstructure in which each sensor tip was embedded. In a $-20^{\circ} \mathrm{C}$ cold room, thin cross sections of ca. 3 to $4 \mathrm{~mm}$ were cut to include and display the optode tips. Sections were photographed under ordinary light for best contrast between the black fibre tip and the pores or brine channels.

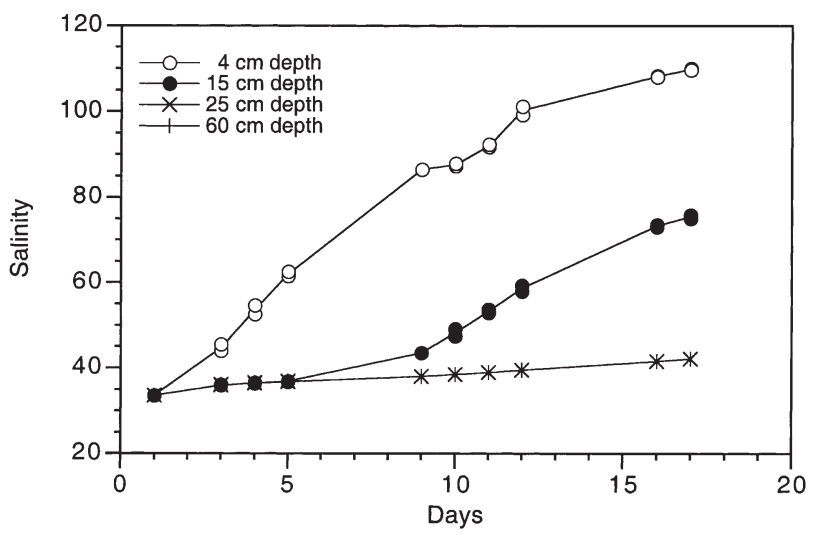

Fig. 4. Shift of calculated brine salinities in those depths where the optodes were placed. Optodes 4, 15, 25 and 60 are at $4,15,25$ and $60 \mathrm{~cm}$ depth, respectively 
Table 1. Chlorophyll a ( $\mathrm{chl}$ a) concentration $\left[\mu \mathrm{g} \mathrm{l}^{-1}\right]$ in brine. $\mathrm{Chl} a$ on Day 3 is given for the entire ice thickness $(5 \mathrm{~cm})$, on Day 10 for top (0 to $7 \mathrm{~cm}$ ) and middle/bottom $(7$ to $14 \mathrm{~cm})$ and on Day 17 for top (0 to $7 \mathrm{~cm}$ ) and middle/bottom (7 to $21 \mathrm{~cm}$ )

\begin{tabular}{|lrrr|}
\hline $\begin{array}{l}\text { Depth in } \\
\text { sea ice }\end{array}$ & 3 & 10 & 17 \\
\cline { 2 - 4 } & & 10.94 & 0.74 \\
Top & 2.65 & 8.78 & 1.23 \\
Middle/bottom & & & \\
\hline
\end{tabular}

\section{RESULTS}

The ice grew at a rate of $0.54 \mathrm{~mm} \mathrm{~h}^{-1}$ after the reduction of room temperature and attained a thickness of $27 \mathrm{~cm}$ by the end of the experiment (Fig. 2). Ice growth was uniform over the surface of the mesocosm, and there were no signs of spatial heterogeneity in ice growth and properties. Consequently, Optodes 4, 15 and 25 were successively frozen into the ice. Optode 4 was frozen on Day 3, Optode 15 on Day 10 and Optode 25 on Day 17, whereas Optode 60 remained in the water as a reference probe. Each of the optodes experienced a different temperature shift during ice formation (Fig. 3). The temperature of Optode 4 decreased from -1.9 to $-6.7^{\circ} \mathrm{C}$, of Optode 15 from -1.9 to $-3.4^{\circ} \mathrm{C}$ and for Optodes 25 and 60 from -1.9 to $-2.2^{\circ} \mathrm{C}$. This general decrease in ice temperatures resulted in an increase of calculated brine salinities from 34 to 110 at $4 \mathrm{~cm}$ depth and from 34 to 78 at $15 \mathrm{~cm}$ depth (Fig. 4). Measured salinities ranged within the same magnitude (Fig. 5). The increase was strongest in the upper parts (from 34 to 77 ), lower in the middle of the ice (from 34 to 62) and a slight increase was measured at the ice-water interface (from 34 to 42). Measured bulk salinities of the ice decreased inversely to the measured brine salinities indicating a desalination of the ice sheet.

The PAR was calculated from the entire under ice spectrum. It decreased from approximately 12 to below $1 \mu \mathrm{mol}$ photons $\mathrm{m}^{-2} \mathrm{~s}^{-1}$ during the experiment, due to increasing ice thickness (Fig. 6).

Algal biomass in terms of chl a fluctuated during ice formation (Table 1). An initial enrichment in brine was measured in the early stages of ice formation especially in the upper parts of the ice (from 2.65 to

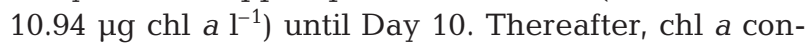
centrations decreased dramatically in the upper parts

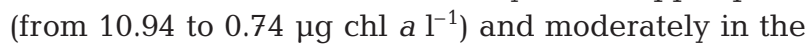
middle and bottom portions (from 8.78 to $1.23 \mu \mathrm{g}$ chl a $\mathrm{l}^{-1}$ ).

Data obtained with the Microx I are calibrated but not corrected for temperature and salinity. The data are given in \% air saturation and integrate both

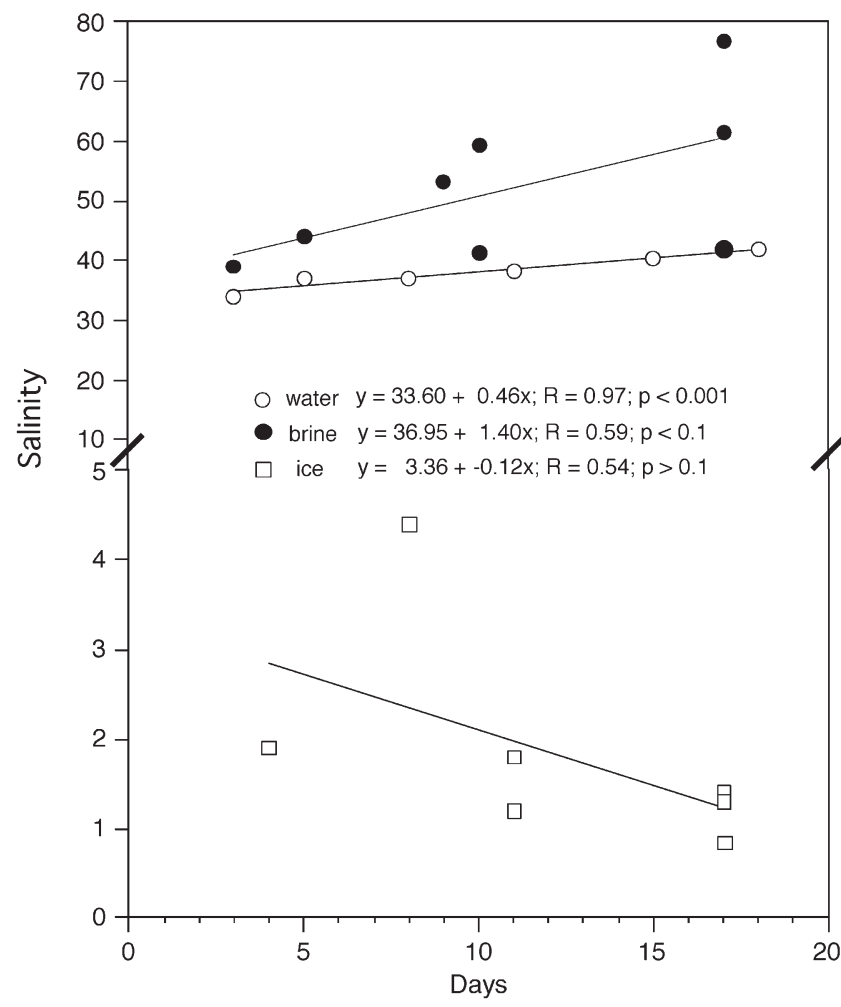

Fig. 5. Water, brine and bulk salinity during sea ice formation

changes in temperature and salinity over time (Fig. 7). Optode 4 recorded oxygen oversaturation in the brine within the top of the sea ice (Fig. 7a), whereas relative oxygen concentrations in the bottom of sea ice, measured with Optode 15 after Day 10, were nearly identical to those of the water below (Fig. 7b,c,d). In general, the temporal trend of oxygen in the water decreased from $89 \pm 4.0$ to $60 \pm 0.5 \%$ air saturation. Temperature

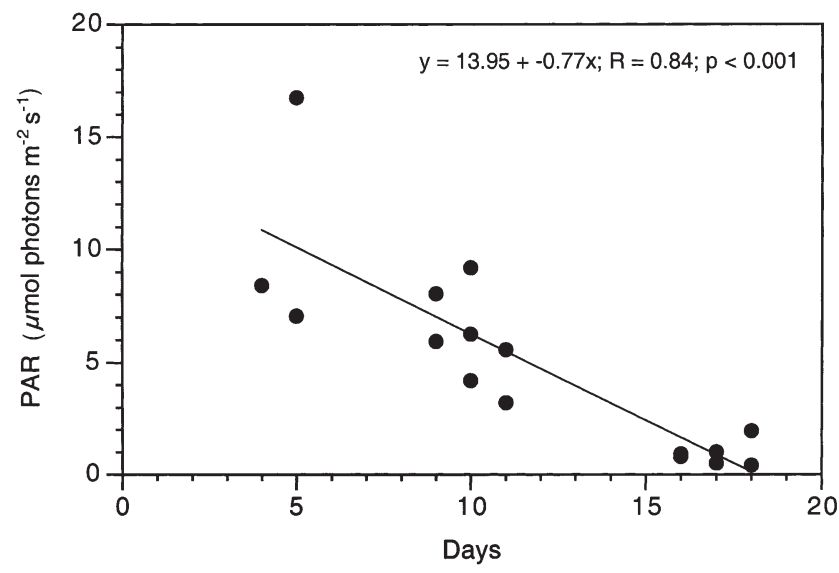

Fig. 6. Irradiance (photosynthetically active radiation = PAR) measured with a miniature fibre optic spectrometer suited $30 \mathrm{~cm}$ below the water surface 

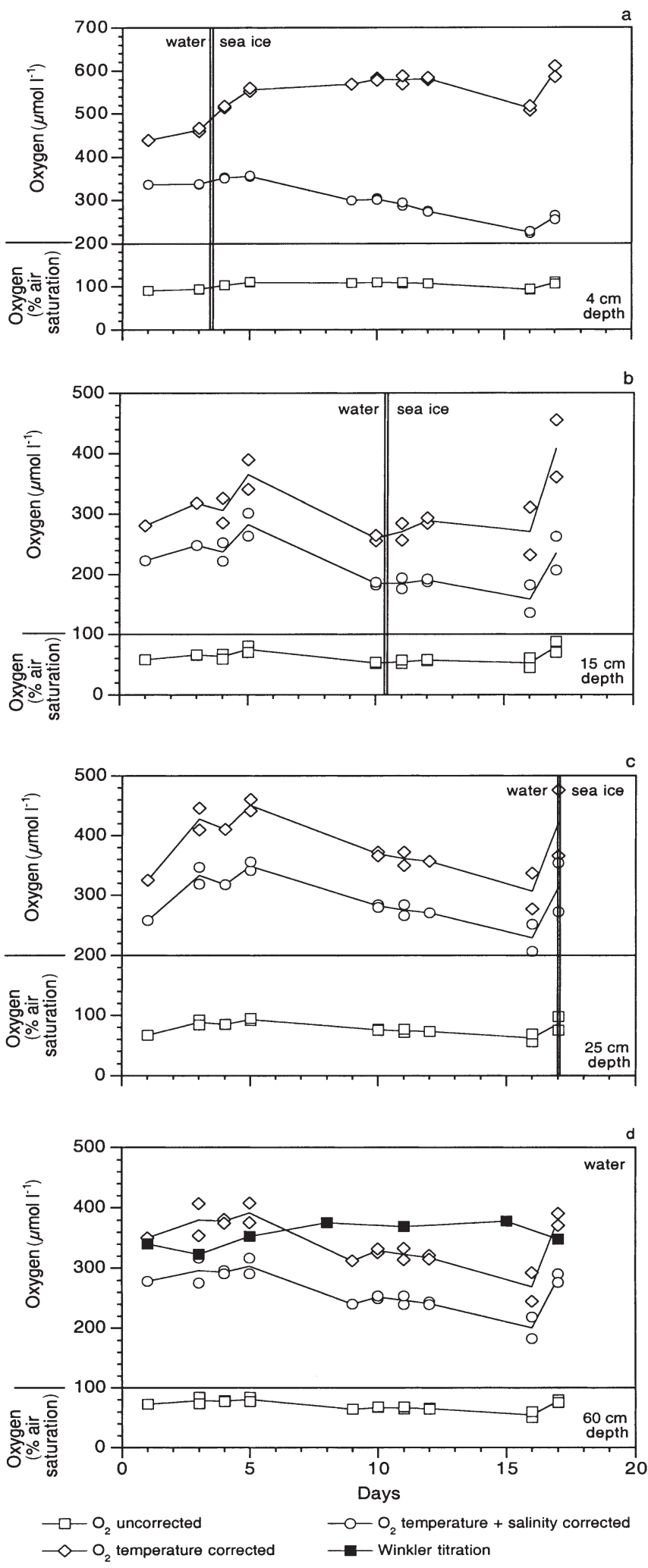

Fig. 7. Oxygen concentrations as \% air saturation $\left(\mathrm{O}_{2}\right.$ uncorrected $)$ and in $\mu \mathrm{mol} \mathrm{l}^{-1}\left(\mathrm{O}_{2}\right.$ temperature corrected; temperature + salinity corrected oxygen measurements) within sea ice and seawater below the ice for (a) Optode 4, (b) Optode 15, (c) Optode 25 and (d) Optode 60 compensation resulted in micromolar oxygen concentrations, which verified the uncorrected Microx I data with regard to the temporal trends. These data also indicated higher oxygen concentrations within the top of the ice compared to the water below. The first significant increase of oxygen occurred on Day 3 of freezing (Optode 4) and in the skeletal layer of the growing ice at Day 10 (Optode 15). The salinity correction takes into account the gassing out effect of oxygen with increasing salinity. This gives the dissolved oxygen concentration under this condition, whereas the temperature corrected as well as the uncorrected data represent both dissolved and gaseous oxygen. This phenomenon of oxygen out-gassing is most pronounced in the top of sea ice, where dissolved oxygen concentrations (temperature and salinity corrected) rapidly decreased with increasing brine salinities (Figs. 4 \& 7a). A small out-gassing event probably also occurred during growth of the skeletal layer (Fig. 7b). Temperature and salinity corrected oxygen concentrations are almost constant over $3 \mathrm{~d}$, whereas the temperature corrected data increased significantly, which was not observed at 25 and $60 \mathrm{~cm}$ water depth (Fig. 7c,d). The chemically determined oxygen concentrations in seawater corresponded well with optode measurements for the first $5 \mathrm{~d}$ of the experiment. Thereafter, Winkler oxygen increased, whereas Optode 60 recorded decreasing values.

Microscopic analyses reveal that each sensor tip was enclosed in a brine channel or pocket (Fig. 8a). Brine channels appear to be narrower in the top of the sea ice (Optode 4) than in the middle (Optode 15) or the skeletal layer (Optode 25). Also, small gas bubbles were more numerous in the top of sea ice than in the middle or bottom parts.

\section{DISCUSSION}

In situ determination of oxygen within a completely undisturbed brine channel system of sea ice has been impossible up to now. Although McMinn \& Asworth (1998), Kühl et al. (2001), Rysgaard et al. (2001) and others, e.g. Trenerry et al. (2002), successfully introduced microelectrodes in sea ice ecology, these studies were either conducted in the diffusive boundary layer between sea ice and seawater with remote-controlled devices (McMinn et al. 2000, Trenerry et al. 2002) or with a tripod and divers (Kühl et al. 2001, Rysgaard et al. 2001). The latter technique enabled measurements of oxygen distribution within loose layers of microalgae just beneath the solid ice cover or even within the lowermost mm of the skeletal layer. However, both techniques have limitations, which are related to the measuring principle of electrodes, their stability, as 
well as the constructions of the devices (Klimant et al. 1997). Oxygen optodes compared to oxygen electrodes do not consume oxygen (Klimant et al. 1995) and they are also able to measure gaseous oxygen. The electrode is immersed in an electrolyte and separated from interfering species by a membrane permeable to oxygen. A flow of dissolved oxygen through this membrane is induced by the consumption of oxygen by the electrode. Non-oxygen consuming sensors, however, are of paramount importance for long-term measurements in semi-enclosed brine channel systems of sea ice. The stability of the optode is guaranteed by the flexibility of the glass fibre and the coating of the sensor with silicon (PreSens). These advantages make the optodes an ideal instrument for determination of oxygen evolution or consumption in brine channels or even enclosed brine pockets. This is only possible by freezing of optodes during sea ice formation, a process, which results in a change of physical and biogeochemical properties of seawater. The effects of such changes on the dynamics of oxygen which is influenced by chemical as well as biological processes are still unknown.

Nevertheless, measurements in small brine channels or even spheres could reveal strong heterogeneity in oxygen concentrations caused by bubble formation and aggregates of either oxygen-producing (algae) or oxygen-consuming organisms (bacteria). One problem during long-term deployment could be the development of bacterial films on the sensor tip, which was not observed during our experiment. Nonetheless, the general differences in oxygen concentrations between the optodes at the beginning of the experiment remains to be resolved because all the optodes were still in the same well-mixed seawater (Fig. 7). With the exception of this problem, optode measurements are able to resolve small scale heterogeneity in sea ice. However, more sensor arrays would need to be deployed to obtain a representative overview of the oxygen dynamics within sea ice. Sack hole sampling of brine is not appropriate because brine collection takes too long, thereby enabling gassing out of hyperoxic brines (Gleitz et al. 1995). Optode measurements are more precise, leading to a better estimate of ecosystem productivity, which varies considerably during different stages of ice algal blooms and inducing dramatic changes in biogeochemical cycles (Günther et al. 1999, Thomas \& Dieckmann 2002).

The discrepancy between temperature corrected (total oxygen: dissolved and gaseous) and salinity corrected oxygen (dissolved oxygen) during ice crystal formation at the water surface and the ice-water interface revealed a strong incorporation of gaseous oxygen, which could be the result of physical entrapment of oxygen producing algae and a salinity increase
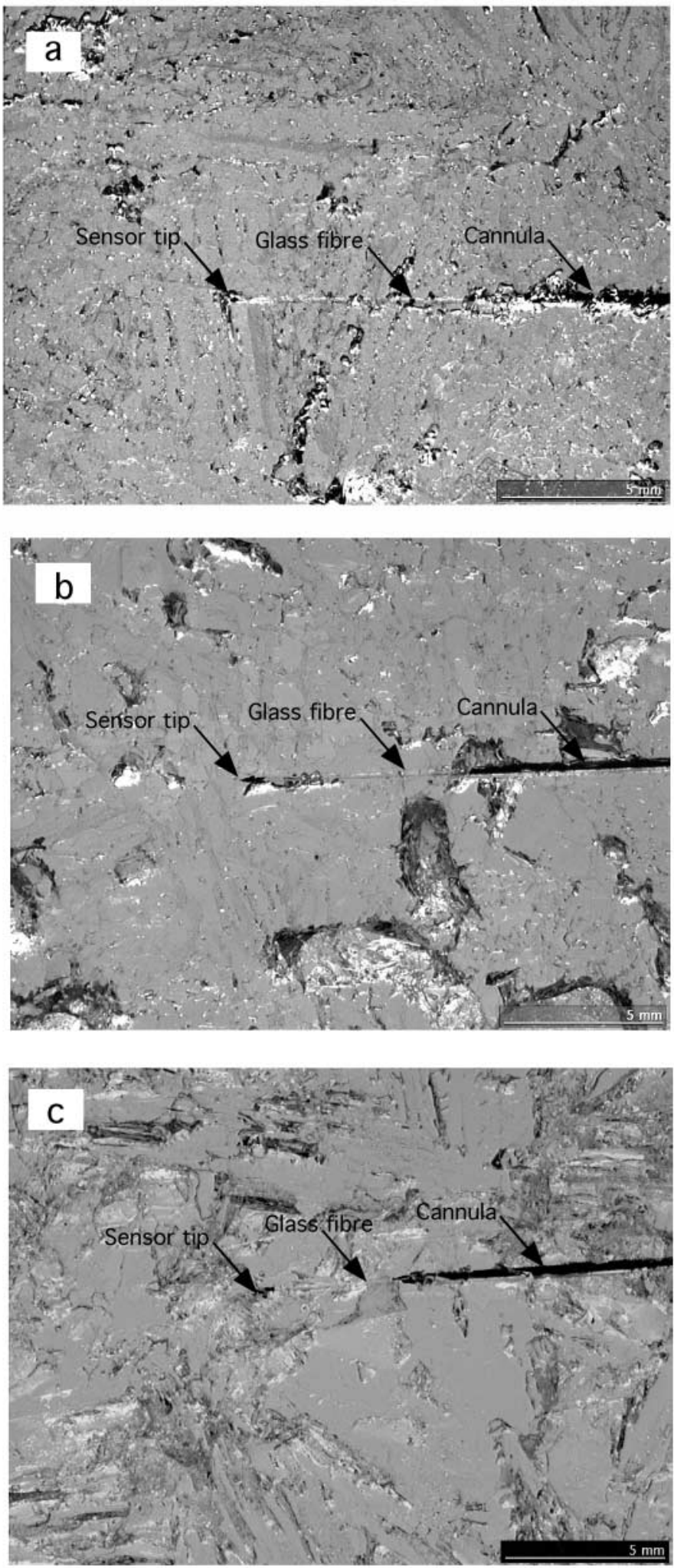

Fig. 8. Thin sections of frozen optodes at the end of the experiment. (a) Optode 4 (4 cm ice depth); (b) Optode 15 (15 cm ice depth); (c) Optode $25(25 \mathrm{~cm}$ ice depth $=$ skeletal layer $)$ 


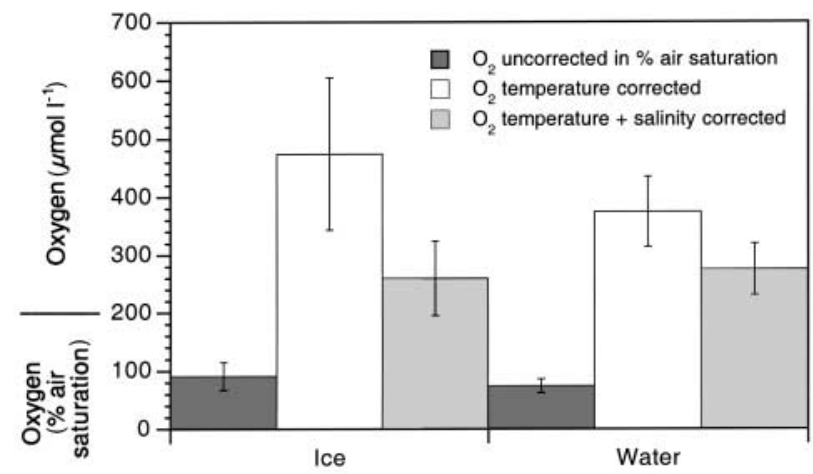

Fig. 9. Ice-water comparison of oxygen either as \% air saturation (uncorrected measurements) or given in $\mu \mathrm{mol}$ oxygen $\mathrm{l}^{-1}$ (temperature corrected; temperature + salinity corrected oxygen measurements)

during freezing. The significantly higher concentration of gaseous oxygen in comparison to dissolved oxygen in sea ice could be elucidated by comparison of total oxygen data for ice and water (Fig. 9). In contrast to sea ice, no significant difference between gaseous and dissolved oxygen could be found in the seawater. It is reasonable to assume that the diatoms were passively accumulated by grease ice formation and that their photosynthetic activity under the higher light intensities at the surface, resulted in the elevated oxygen concentrations. The brine channels could therefore be oversaturated with oxygen, resulting in a release of gaseous oxygen from sea ice (see uncorrected data of Optode 4). This is also indicated by high concentrations of gas bubbles around Optode 4 (Fig. 8). A physical entrapment of oxygen within the primary ice layer at the water surface at a time when it consisted of separate crystals can also be assumed. The oxygen is probably incorporated partly from the atmosphere and partly from the water (Matsuo \& Miyake 1966, Tsurikov 1979). Experiments with microelectrodes in artificial sea ice by Glud et al. (2002) confirmed the observation that brine is supersaturated while melt water is undersaturated with respect to dissolved oxygen. They speculated that the major portion of oxygen associated with the sea ice matrix is most likely trapped as gas bubbles that developed during the freezing process, which is confirmed by our measurements. Nevertheless, both physical and biological processes influence the gaseous oxygen in newly formed sea ice. Increasing salinities due to decreasing ice temperatures reduce the maximum concentration of dissolved oxygen within brine channels. The higher the brine salinity, the lower the maximum oxygen concentration which can be dissolved. This chemical relationship is assumed to be the reason for a temporal decrease in dissolved oxygen concentrations within sea ice (temperature and salinity corrected data of Optode 4). This salinity effect is most pronounced in the top of sea ice where ice is colder in comparison to the ice-water interface. However, the dynamics of oxygen at the ice-water interface is, in contrast, probably influenced by physically trapped oxygen and activity of algal communities, dominating the bottom habitat because the salinity difference to sea water was less pronounced here. Optode 15 recorded an increase in total oxygen (temperature corrected oxygen) during skeletal layer formation from Days 10 to 12 . The highest biomass in terms of chl $a$ in this layer and a strong reduction of biomass in the top layers was also recorded during this time. A release of gas from solution during subsequent freezing of sea water at the icewater interface also occurs during ice growth (Tsurikov 1979). Winkler titrations and optode measurements (Fig. 7) confirmed the release of oxygen during sea ice formation between Days 3 and 5. However, the oxygen concentrations in water remained almost constant after Day 5 as determined by Winkler, whereas optode measurements revealed decreasing values (Fig. 7b,c,d; water).

Salinity and density of brine in the upper layer of the sea ice increase because of the rejection of salt by the growing ice sheet. This caused desalination of the ice, which is confirmed by decreasing bulk salinities during freezing (Fig. 5) and generated an unexpected high loss of initially trapped diatoms. Nevertheless, such changes in pigment concentration could also be caused by changes of chl a:carbon ratios, which probably decreased due to increasing irradiance in the top of sea ice. Photosynthesis of diatoms at the sea ice surface was more likely inhibited by high salinities and low temperatures, whereas diatoms at the sea ice-water interface were probably inhibited by low photon flux densities of not more than $1 \mu \mathrm{mol}$ photons $\mathrm{m}^{-2} \mathrm{~s}^{-1}$ (Fig. 6). Nutrient limitation could be excluded in the artificial seawater enriched by $\mathrm{f} / 2$ nutrients.

The measurements with micro-optodes have improved our understanding of oxygen dynamics in sea ice, which is vital for modelling biogeochemical cycles (Thomas \& Dieckmann 2002). This method combined with novel measurements by Eicken et al. (2000) using magnetic resonance imaging (MRI) to investigate small scale processes in changing temperature regimes occurring during sea ice formation may help to better understand the dramatic influence of gas dynamics in sea ice and related biological activity. Optical observations to investigate microstructural influences on the distribution of algae and bacteria (Junge et al. 2001) would complete the detailed investigation of small scale microstructural processes within sea ice brine channels and pockets. 


\section{CONCLUSIONS}

This study demonstrated the first use of microoptodes to investigate oxygen dynamics within undisturbed brine channels of sea ice. Although experiments were done in an artificial experimental tank, the results give reason to believe that further developments will enable their deployment in the field. The sensors are a significant advance over more conventional microelectrodes. They are ideal for long-term deployment in the field because they can be temperature and salinity compensated and do not consume oxygen during measurements over a long period under low temperatures. The optodes withstand freezing without damage to the sensor tip, an important prerequisite to measure directly within brine channels or brine pockets of sea ice without disturbing the ice texture or brine chemistry. Evidently, both physicochemical and biological processes influence the oxygen concentrations in sea ice. Oxygen is obviously incorporated during sea ice formation and enhanced by photosynthetic activity of micro-algae, resulting in supersaturation, especially in the top layers of sea ice. However, the major proportion of oxygen is not dissolved in brine, but is concentrated in the form of air bubbles or released to the seawater.

Acknowledgements. We would like to thank the Hamburg Ship Model Basin (HSVA), especially K. U. Evers and the ice tank crew, for hospitality, technical support and professional execution of the test programme in the ARTECLAB. The research activities carried out at the Major Research Infrastructure ARTECLAB were granted by the Human Potential and Mobility Programme from the European Union through grant: HPRI-CT-1999-00035. D.N.T. is grateful also to the support of the Hanse Institute of Advanced Study and a NERC small research grant to the Bangor group. Special thanks are given to Erika Allhusen for her excellent technical assistance.

\section{LITERATURE CITED}

Alexander V, Horner R, Clasby CR (1974) Metabolism of Arctic sea ice organisms, Rep R74-4. Institute of Marine Science, University of Alaska, Fairbanks, p 1-120

Arar EJ, Collins GB (1992) In vitro determination of chlorophyll $a$ and phaeophytin $a$ in marine and freshwater phytoplankton by fluorescence. Method 445.0. In: US EPA (ed) Methods for the determination of chemical substances in marine and estuarine environmental samples. US Environmental Protection Agency, Cincinnati

Arrigo KR, Worthen DL, Lizotte MP, Dixon P, Dieckmann G (1997) Primary production in Antarctic sea ice. Science 276:394-397

Assur A (1960) Composition of sea ice and its tensile strength. SIPRE Res, Rep 44, Wilmette, IL, p 1-49

Brierley AS, Thomas DN (2002) The ecology of Southern Ocean sea ice. Adv Mar Biol 43:171-276

Bunt JS, Lee CC (1970) Seasonal primary production in Antarctic sea ice at McMurdo Sound in 1967. J Mar Res 28:304-320
De Beer D, Glud A, Epping E, Kühl M (1997) A fast-responding $\mathrm{CO}_{2}$ microelectrode for profiling sediments, microbial mats, and biofilms. Limnol Oceanogr 42(7):1590-1600

Dieckmann G, Lange M, Ackley SF, Jennings J Jr (1991) The nutrient status in sea ice of the Weddell Sea during winter: effects of sea ice texture and algae. Polar Biol 11:449-456

Eicken H, Bock C, Wittig R, Miller H, Poertner HO (2000) Magnetic resonance imaging of sea-ice pore fluids: methods and thermal evolution of pore microstructure. Cold Reg Sci Technol 31:207-225

Gleitz M, Vonderloeff MR, Thomas DN, Dieckmann GS, Millero FJ (1995) Comparison of summer and winter inorganic carbon, oxygen and nutrient concentrations in Antarctic sea ice brine. Mar Chem 51(2):81-91

Glud RN, Rysgaard S, Kühl M (2002) A laboratory study on $\mathrm{O}_{2}$ dynamics and photosynthesis in ice algal communities: quantification by microsensors, $\mathrm{O}_{2}$-exchange rates, ${ }^{14} \mathrm{C}$ incubation and PAM fluorometer. Aquat Microb Ecol 27:301-311

Gouin JF, Baros F, Birot D, Andre JC (1997) A fibre-optic oxygen sensor for oceanography. Sensors Actuators B 38-39: 401-406

Grossmann S, Dieckmann GS (1994) Bacterial standing stock, activity, and carbon production during formation and growth of sea ice in the Weddell Sea, Antarctica. Appl Environ Microbiol 60:2746-2753

Guillard RR, Ryther JH (1962) Studies of marine plankton diatoms. I. Cyclotella nana (Husted) and Detonula confervacea (Cleve). Can J Microbiol 8:229-239

Günther S, Dieckmann GS (1999) Seasonal development of algal biomass in snow-coverd fast ice and the underlying platelet layer in the Weddell Sea, Antarctica. Antarct Sci 11(3):305-315

Günther S, Gleitz M, Dieckmann GS (1999) Biogeochemistry of Antarctic sea ice: a case study on platelet ice layers at Drescher Inlet, Weddell Sea. Mar Ecol Prog Ser 177:1-13

Haas C, Cottier F, Smedsrud LH, Thomas D and 7 others (1999) Multidisciplinary ice tank study shedding new light on sea ice growth processes. EOS 80(43):507-513

Herman HB, Rechnitz GA (1974) Preparation and properties of a carbonate ion-selective membrane electrode. Anal Chim Acta 76:155-164

Horner R (1985) Sea ice biota. CRC, Boca Raton

Jörgensen BB, Revsbech NP (1985) Diffusive boundary layers and the oxygen uptake of sediments and detritus. Limnol Oceanogr 30:111-122

Junge K, Krembs C, Deming J, Stierle A, Eicken H (2001) A microscopic approach to investigate bacteria under in situ conditions in sea ice samples. Ann Glaciol 33:304-310

Kirst GO, Wiencke C (1995) Ecophysiology of polar algae. J Phycol 31:181-199

Klimant I, Meyer V, Kühl M (1995) Fiber-optic oxygen microsensors, a new tool in aquatic biology. Limnol Oceanogr 40:1159-1165

Klimant I, Kühl M, Glud RN, Holst G (1997) Optical measurement of oxygen and temperature in microscale: strategies and biological applications. Sensors Actuators B 38-39: 29-37

Krembs C, Gradinger R, Spindler M (2000) Implications of brine channel geometry and surface area for the interaction of sympagic organisms in Arctic sea ice. J Exp Mar Bio Ecol 243:55-80

Krembs C, Mock T, Gradinger R (2001) A mesocosm study of physical-biological interactions in artificial sea ice: effects of brine channel surface evolution and brine movement on algal biomass. Polar Biol 24:356-364

Kühl M, Glud RN, Borum J, Roberts R, Rysgaard S (2002) 
Photosynthetic performance of surface associated algae below sea ice as measured with a pulse amplitude modulated (PAM) fluorometer and $\mathrm{O}_{2}$ microsensors. Mar Ecol Prog Ser 223:1-14

Legendre L, Ackley SF, Dieckmann GS, Gulliksen B and 6 others (1992) Ecology of sea ice biota. 2. Global significance. Polar Biol 12:429-444

Lizotte M P (2001) The contributions of sea ice algae to Antarctic marine primary production. Am Zool 41:57-73

Matsuo S, Miyake Y (1966) Gas composition in ice samples from Antarctica. J Geophys Res 71(22):5235-5241

McMinn A, Ashworth C (1998) The use of oxygen microelectrodes to determine the net production by an Antarctic sea ice algal community. Antarct Sci 10:39-44

McMinn A, Ashworth C, Ryan KG (2000) In situ net primary productivity of an Antarctic fast ice bottom algal community. Aquat Microb Ecol 21:177-185

Meguro H (1962) Plankton ice in the Antarctic ocean. Antarct Rec 14:1192-1199

Melnikov IA (1997) The Arctic sea ice ecosystem. Gordon and Breach Science Publishers, Amsterdam

Mock T, Gradinger R (1999) Determination of Arctic ice algal production with a new in situ incubation technique. Mar Ecol Prog Ser 177:15-26

Revsbech NP, Jörgensen BB (1986) Microelectrodes: their use in microbial ecology. In: Marshall KC (ed) Advances in

Editorial responsibility: Karin Lochte, Kiel, Germany microbial ecology, Vol 9. Plenum Press, New York, p 293-352

Revsbech NP, Jörgensen BB, Blackburn TH (1980) Oxygen in the sea bottom measured with a microelectrode. Science 207:1355-1356

Rysgaard S, Kühl M, Glud RN, Hansen JW (2001) Biomass, production and horizontal patchiness of sea ice algae in a high-Arctic fjord (Young Sound, NE-Greenland). Mar Ecol Prog Ser 223:15-26

Sherwood JE, Stagnitti F, Kokkin MJ, Williams WD (1991) Dissolved oxygen concentrations in hypersaline waters. Limnol Oceanogr 36(2):235-250

Strickland JD, Parsons TR (1972) A practical handbook of sea water analysis. Bull Fish Res Board Can 167:310

Thomas DN, Dieckmann GS (2002) Antarctic Sea ice-a habitat for extremophiles. Science 295:641-644

Thomas DN, Kennedy H, Kattner G, Gerdes D, Gough C, Dieckmann GS (2001) Biogeochemistry of platelet ice: its influence on particle flux under fast ice in the Weddell Sea, Antarctica. Polar Biol 24:486-496

Trenerry LJ, McMinn A, Ryan KG (2002) In situ oxygen microelectrode measurements of the bottom-ice algal production in McMurdo Sound, Antarctica. Polar Biol 25:72-80

Tsurikov VL (1979) The formation and composition of the gas content of sea ice. Journal of Glaciology 22:67-81

Submitted: January 14, 2002; Accepted: June 14, 2002

Proofs received from author(s): September 19, 2002 